University of Nebraska - Lincoln

DigitalCommons@University of Nebraska - Lincoln

Nebraska Swine Reports

Animal Science Department

January 2000

\title{
Effect of Wean-to-Finish Management on Pig Performance
}

Mike Brumm

University of Nebraska, mbrumm@hickorytech.net

Angela K. Baysinger

Alpharma Animal Health, Fort Lee, NJ

Robert W. Wills

University of Nebraska-Lincoln

Edgar T. Clemens

University of Nebraska-Lincoln

Robert C. Thaler

South Dakota State University, Brookings

Follow this and additional works at: https://digitalcommons.unl.edu/coopext_swine

Part of the Animal Sciences Commons

Brumm, Mike; Baysinger, Angela K.; Wills, Robert W.; Clemens, Edgar T.; and Thaler, Robert C., "Effect of Wean-to-Finish Management on Pig Performance" (2000). Nebraska Swine Reports. 107.

https://digitalcommons.unl.edu/coopext_swine/107

This Article is brought to you for free and open access by the Animal Science Department at DigitalCommons@University of Nebraska - Lincoln. It has been accepted for inclusion in Nebraska Swine Reports by an authorized administrator of DigitalCommons@University of Nebraska - Lincoln. 


\section{Effect of Wean-to-Finish Management on Pig Performance}

\author{
Michael C. Brumm \\ Angela K. Baysinger \\ Robert W. Wills \\ Edgar T. Clemens \\ Robert C. Thaler ${ }^{1}$
}

\section{Summary and Implications}

An experiment consisting of three trials was conducted to determine the effect of wean-to-finish management systems on pig performance. Treatments consisted of: 1) wean-to-finish single stock (WF) at $7.5 \mathrm{ft}^{2} /$ pig from weaning (17 day mean age) to slaughter in a fully slatted finishing facility; 2) double stock (DS) at $3.75 \mathrm{ft}^{2} / p i g$ for eight weeks following weaning and then split into two pens at $7.5 \mathrm{ft}^{2} / \mathrm{pig}$ each; and 3) nursery (NF) at $3.75 \mathrm{ft}^{2} /$ pig for eight weeks in a conventional nursery followed by movement to the finisher and stocked at $7.5 \mathrm{ft}^{2} /$ pig to slaughter. All pens had one two-hole wean-finish dry feeder per 15 pigs and one cup-drinker per 15 pigs. While there were health related performance problems in Trials 1 and 2 due to PRRS, there were no trial by treatment interactions. At the end of eight weeks, $W F$ pigs were heavier $(P<.01)$ than $D S$ pigs with NF pigs intermediate in weight (63.1, 59.2, and 60.9lbs, respectively). The heavier weight was due to a difference $(P<.01)$ in feed intake between the WF and DS treatments. There was no effect of nursery phase treatment on feed efficiency. There was no effect $(P>.1)$ of any management treatment on any grow-finish phase production parameter reported. These data suggest that the performance improvement associated with wean-to-finish production systems occurs during the first eight weeks postweaning. They also suggest that the response can be expected even when health challenges occur in a production system.

\section{Introduction}

Designing production systems for pig flow used to be relatively simple. Following weaning, pigs were moved to a nursery for four to eight weeks and then moved to a grower-finisher facility. The nursery was designed for pigs from 10 to 45 pounds and the growerfinisher was for pigs from 45 pounds to slaughter. Engineers, farm managers and consultants all had experiences with these facilities. They knew what the temperature requirements and associated heating costs were, what stocking density gave the best pig performance and economic return, and how much manure was produced per facility each year.

The advent of wean-to-finish facility management has changed many producers' thoughts regarding facility needs and pig flow considerations. Instead of designing nurseries for six to eight groups of pigs per year (turns) and finishers for 2.7 to 2.8 turns per year, wean-to-finish facilities are designed for 2.1 turns per year. Instead of having one nursery and two finishers as the ideal planning combination, we now are concerned about pairing up wean-to-finish facilities having 2.1 turns per year with finishers having 2.7 turns per year. Producers, engineers and their advisers are asking questions about stocking strategies to maximize performance and economic return, manure production values for environmental regulators, heating systems, feeder selection and a host of related questions.

While the popular press has carried numerous reports of producer experiences with wean-finish facilities, there have been no published studies designed to compare the effects of common management systems on weaned pig performance to slaughter.

\section{Materials and Methods}

This research investigated the effects of three weaned pig management systems on performance from weaning to slaughter. The systems were:

1) Wean-to-finish (WF). Pigs were weaned into fully slatted finishing pens stocked at 7.5 $\mathrm{ft}^{2} /$ pig from weaning to slaughter.

2) Double stock (DS). Pigs were weaned into fully slatted finishing pens at $2 \mathrm{x}$ the density of WF (3.75 $\left.\mathrm{ft}^{2} / \mathrm{pig}\right)$. Eight weeks after weaning, the pigs were randomly divided into two groups, with one group remaining in the same pen and the other relocated to another pen in the same facility. Pigs then were grown to slaughter at $7.5 \mathrm{ft}^{2} / \mathrm{pig}$.

3) Nursery moved to finisher (NF). Pigs were weaned into a nursery and stocked at 3.75 $\mathrm{ft}^{2} /$ pig. Eight weeks after weaning, they were relocated to the same finisher as WF and DS and grown to slaughter at $7.5 \mathrm{ft}^{2} / \mathrm{pig}$.

The growing-finishing facility used in this research is located at the University of Nebraska's Haskell Ag (Continued on next page) 
Laboratory near Concord, Neb. It is a five-year-old double wide, naturally ventilated, fully slatted facility with 8 foot $x 14$ foot pens. The cement slats are 7 inches wide with a 1 inch slot.

The nursery was mechanically ventilated with unvented heaters. Pens with 5 ga woven wire flooring measured 8 feet $x 8$ feet with a gate inserted in one corner to restrict usable pen area to $56.25 \mathrm{ft}^{2}$. Minimum winter ventilation was provided by a single speed fan exhausting from the manure storage area under the decks. Because of reduced pig density in this experiment, the minimum ventilation was 6.7 CFM/pig.

There were 15 pigs per pen for the WF and NF treatments and 30 pigs per pen for the DS. Pen size was not adjusted in the event of pig death. There was a two-hole wean-finish feeder and one bowl-drinker for every 15 pigs. Heat lamps were used as the supplemental heat source for the WF and DS treatments. Comfort mats were used in all treatments and pigs were floor fed $3 \mathrm{X}$ daily for the first week after weaning.

A commercially available nursery diet sequence was used. Diets were switched during the eight-week nursery phase based on a preplanned feed budget to $40 \mathrm{lbs}$ body weight. Cornsoybean meal based diets in meal form containing $2 \%$ added fat were formulated to contain $1.1 \%$ lysine from 40 to $55 \mathrm{lbs}, 1.0 \%$ lysine from 55 to $80 \mathrm{lbs}$, $.88 \%$ lysine from 80 to $130 \mathrm{lbs}, .73 \%$ lysine from 130 to $190 \mathrm{lbs}$, and .60\% lysine from $190 \mathrm{lbs}$ to slaughter.

Temperatures in the nursery were maintained at 84 to $86^{\circ} \mathrm{F}$ the first week after weaning and were programmed to decline 3 to $4 \mathrm{~F}^{\circ}$ per week thereafter until $70^{\circ} \mathrm{F}$. However, two of the three trials began in April and by mid-May the planned reduction in temperature could not be accomplished because of higher outside air temperatures. Air temperature in the finishing facility was maintained at 73 to $76^{\circ} \mathrm{F}$ with heat lamps used for supplemental heat as necessary. Heat lamps were removed after three to five weeks, depending on the need for supplemental heat.
Pigs were weaned at 17 days of age and transported to the research unit at weaning. In Trials 1 and 2, the pigs were purchased from a source 100 miles away, and in Trial 3 they were from a source 70 miles away. Pigs were barrow offspring of PIC genetic crosses. Trials were started in April and October in an attempt to pair up heating seasons and minimize any effects of season due to large variations in heating expenses.

\section{Results and Discussion}

In Trials 1 and 2, gut edema was diagnosed by attending veterinarians on weeks two through four following weaning. It was most severe in the WF and DS treatments. In Trial 1, only the WF and DS treatments received medication while in Trial 2, all pigs were medicated. There was no evidence of gut edema in Trial 3.

The diagnosis of gut edema coincided with an increase in messy pens. For the first four to six weeks after weaning, the pigs walked "with" the cement slat and dunged on top of the slat. They then tracked this material throughout the pen with tracking reaching its peak about four weeks after weaning. The only dry area in the pen was directly under the heat lamp vs the nursery treatment with woven wire flooring which had no tracking of manure. Based on gross observations, it appeared that there were increased humidity and ammonia levels due to this tracking in the WF/DS facility.

Pigs in Trials 1 and 2 had many health challenges due to complications associated with PRRS, while in Trial 3 , no such complications were evident. However, there was no trial by treatment interaction for pig performance during the nursery phase, suggesting that health status of the pigs was not a factor in the response to wean-to-finish management during the nursery phase.

In spite of the health problems noted for Trials 1 and 2 and the differential treatment of gut edema, WF pigs performed better than DS and NF pigs during the nursery phase (Table 1). The response appears to be due to greater feed intake, resulting in faster daily gain, with no difference in feed conversion. Even though temperatures in the nursery were set on the low end of the thermoneutral zone to limit the possibility of heat stress during the nursery phase, feed intake was lower for the NF vs WF treatments.

The reduction in performance for DS vs WF is probably related to group size. In the range of group sizes used in this experiment, there is good evidence that increasing group sizes results in a decrease in daily feed intake and daily gain. However, the reduction in individual pig performance doesn't outweigh the overall improvement in pig weight gain per unit of floor space, a critical factor when assessing the economics of various wean-to-finish strategies.

Many would argue that the NF treatment allocated too much space per pig compared to conventional nurseries which are typically stocked at no more than $3 \mathrm{ft}^{2}$ per pig. This space allocation was chosen to: 1) match the allocation of the DS treatment, and 2) provide sufficient space so there would be a minimal chance that space restriction during the nursery phase would negatively affect performance. It's quite possible that many of the reports in the popular press of improved performance for wean-tofinish are due to nursery facility limitations. These limitations involve inadequate space, improper feeder design for the heavier pigs now common in nurseries, improper temperature sequencing, etc. The NF treatment was designed to remove these limitations if possible.

Wean-to-finish treatments did not affect performance during the growing-finishing phase (Table 2). Average daily gain was similar for WF, double stocked pigs that remained in the same pen (DSS), double stocked pigs that were moved to new pens (DSM) and NF pigs. Treatment also did not affect variation in weight within a pen as judged by the within pen coefficient of variation of weight when the first pig from the pen was marketed. There was also no effect of treat- 
Table 1. Impact of wean-to-finish regimens on weaned pig performance during the nursery phase.

\begin{tabular}{|c|c|c|c|c|c|}
\hline \multirow[b]{2}{*}{ Item } & \multicolumn{3}{|c|}{ Regimen $^{\mathrm{a}}$} & \multicolumn{2}{|c|}{ Contrasts } \\
\hline & WF & DS & NF & WF vs NF & WF vs DS \\
\hline No.pens & 12 & 12 & 12 & & \\
\hline Weaning wt, lb & 11.2 & 11.2 & 11.2 & $\mathrm{NS}^{\mathrm{b}}$ & NS \\
\hline 56 day wt, $1 \mathrm{~b}$ & 63.1 & 59.2 & 60.9 & NS & $<.01$ \\
\hline CV 56 day wt $\%^{\mathrm{c}}$ & 14.6 & 17.0 & 14.7 & NS & NS \\
\hline Average daily gain, $l b$ & .92 & .86 & .89 & NS & $<.01$ \\
\hline Average daily feed, $1 \mathrm{~b}$ & 1.53 & 1.42 & 1.47 & $<.1$ & $<.01$ \\
\hline Feed:Gain & 1.66 & 1.66 & 1.64 & NS & NS \\
\hline
\end{tabular}

${ }^{\mathrm{a}} \mathrm{WF}$ - wean-to finish; DS - Double stock; NF - Nursery.

${ }^{\mathrm{b}} \mathrm{NS}$ - Not significant $(\mathrm{P}>\mathrm{.1})$.

${ }^{\mathrm{c}}$ Coefficient of variation of within pen weight.

Table 2. Impact of wean-to-finish regimens on pig performance during the finishing phase.

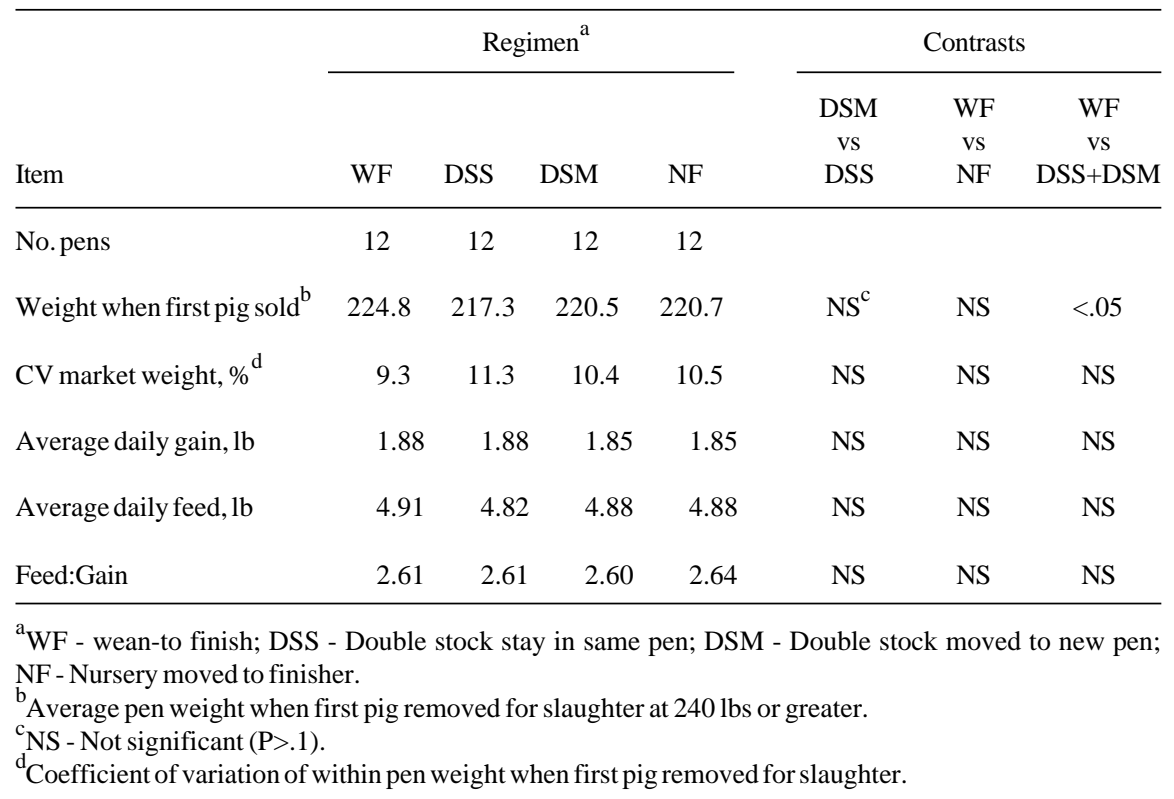

ment on daily feed intake or feed conversion efficiency.

The four-pound advantage at 56 days for NF vs DS (Table 1) translated into a 2+ day advantage to market since there was no difference between treatments in daily gain during the grow-finish period. With weekly weighings and a numeric, but nonsignificant reduction in weight variation within a pen, WF pigs were 5.9 pounds heavier than the average of both DS and NF treatments when the first pig weighting 240 pounds or greater was removed for slaughter.

\section{Conclusion}

These results support the reports in the farm press of improved performance for pigs housed in wean-tofinish management systems. Feed intake during the nursery phase was elevated for wean-to-finish housed pigs, resulting in faster daily gains during the eight-week nursery period. The lack of trial by treatment interactions suggests that the response is not influenced by the health status of the pigs during the nursery period. These results will be used in a production system model to examine the economics of wean-tofinish production systems versus conventional systems with nurseries and grow-finish facilities.

${ }^{1}$ Michael C. Brumm is a professor of animal science, University of Nebraska-Lincoln. Angela K. Baysinger was a technical service veterinarian with Alpharma Animal Health, Fort Lee, NJ. Robert W. Wills is an assistant professor of veterinary and medical sciences, EdgarT. Clemens is a professor of animal science, University of Nebraska-Lincoln. Robert C. Thaler is a professor of animal and range science at South DakotaState University, Brookings. 